\title{
The need for comparative data in spondyloarthritis
}

\author{
Ernest Choy ${ }^{1 *}$, Xenofon Baraliakos ${ }^{2}$, Frank Behrens ${ }^{3}$, Salvatore D'Angelo ${ }^{4}$, Kurt de Vlam ${ }^{5}$, Bruce W. Kirkham ${ }^{6}$, \\ Mikkel Østergaard ${ }^{7}$, Georg A. Schett ${ }^{8}$, Michael Rissler $^{9}$, Kamel Chaouche-Teyara $^{9}$ and Chiara Perella ${ }^{9}$
}

\begin{abstract}
Spondyloarthritis comprises a group of inflammatory diseases, characterised by inflammation within axial joints and/or peripheral arthritis, enthesitis and dactylitis. An increasing number of biologic treatments, including biosimilars, are available for the treatment of spondyloarthritis. Although there are a growing number of randomised controlled trials assessing treatments in spondyloarthritis, there is a paucity of data from head-to-head studies. Comparative data are required so that clinicians and payers have the level of evidence required to inform clinical decision-making and health economic assessments. In the absence of head-to-head studies, statistical methods such as network meta-analyses and matching-adjusted indirect comparisons (MAICs) are used for assessing comparative effectiveness.

Network meta-analysis can be used to compare treatments for trials using a common comparator (e.g. placebo); however, for those without a common comparator or where considerable heterogeneity exists between the study populations, a MAIC that controls for differences in study design and baseline patient characteristics may be used. MAICs, unlike network meta-analyses, are of value for longer-term comparisons beyond the placebo-controlled phase of clinical trials, which is important for chronic diseases requiring long-term treatment, like spondyloarthritis. At present, there are a number of limitations that restrict the effectiveness of MAIC, such as the poor availability of individual patient-level data from trials, which results in patient-level data from one trial being compared with published wholepopulation data from another. Despite these limitations, drug reimbursement agencies are increasingly accepting MAIC as a means of comparative effectiveness and greater methodological guidance is needed.

This report highlights a number of challenges that are specific to conducting comparative studies like MAIC in spondyloarthritis, including disease heterogeneity, the paucity of biomarkers and the duration of studies required for radiographic endpoints in this slow-progressing disease.
\end{abstract}

Keywords: Biological therapy, Clinical trials, Psoriatic arthritis, Radiography, Spondyloarthropathy

\section{Background}

Spondyloarthritis $(\mathrm{SpA})$ represents a group of inflammatory arthritides, mainly axial SpA and psoriatic arthritis (PsA), which share common genetic features and a chronic clinical course. There are a growing array of biologic agents and biosimilar medications, targeting key mediators involved in the inflammatory process, available to rheumatologists. Although there are an increasing number of randomised controlled trials (RCTs) assessing treatments in SpA, there is a paucity of data from head-to-head studies, so other forms of treatment comparison are needed.

\footnotetext{
*Correspondence: ChoyEH@cardiff.ac.uk

${ }^{1}$ CREATE Centre, Division of Infection and Immunity, Cardiff University School of Medicine, Wales, UK

Full list of author information is available at the end of the article
}

This commentary summarises the key findings of an industry-sponsored roundtable discussion involving eight expert rheumatologists and two medical personnel from the pharmaceutical industry, that was conducted in April 2017 to obtain advice and perspectives on comparative studies in SpA.

\section{Network meta-analyses and MAICs}

Indirect comparisons can infer the relative effectiveness of different treatments. For trials using common comparators (e.g. Drug A vs Drug B and Drug B vs Drug C), treatments can be indirectly compared using a network meta-analysis [1]. Where there is no common comparator to facilitate a network meta-analysis, or where considerable heterogeneity exists between the study populations, a matching-adjusted 
indirect comparison (MAIC) that controls for differences in study design and baseline patient characteristics may be used $[1,2]$. Significant debate exists regarding which indirect comparison method is optimal (Table 1) $[3,4]$.

Several MAICs have been published comparing biologics for the treatment of AS [5-12] and PsA [13-24], although only two as full-length papers $[13,25]$; these analyses compare patient-level data from a trial of a given treatment (i.e. index trial) with published data for another treatment (Table 2) [1]. Until the National Institute of Health and Care Excellence (NICE) published technical guidance on this topic in December 2016 [2], the lack of quality criteria made it challenging to interpret the results of MAICs; however, further methodological guidance would be of value.

\section{Key points to consider for MAICs}

First, making individual patient-level data available from trials will facilitate MAIC and circumvent the need to compare patient-level data from one trial with published whole-population data from another. Second, selection of baseline parameters for matching is critical. Ideally, these should be based on established key parameters that are known, from published data and expert opinion, to influence outcomes. Third, when placebo response is available, this can inform quality of matching. Additionally, anchored comparisons (i.e. having a common comparator) are preferred to unanchored analysis [26]. Fourth, if the number of patients included after matching is small, caution is needed when inferring results. Fifth, sensitivity analyses should be conducted, varying the matching parameters to assess the robustness of results or cross-validating the results using data from other trials. Lastly, a thorough and detailed description of the methodology is essential when reporting results.

\section{Challenges for MAICs in spondyloarthritis}

In comparison to rheumatoid arthritis, SpA has a heterogeneous clinical presentation characterised by inflammation affecting the axial skeleton (the spine and sacroiliac joints), peripheral joints and entheses and extra-articular sites, such as the eye (uveitis), skin (psoriasis) and gut (inflammatory bowel disease [IBD]) [27] . This heterogeneity adds complexity when defining the inclusion criteria for a clinical study population and also for any subsequent MAIC that might only include a subset of the index population in order to match the comparator population. Treatment history is also important, as many newer studies include patients who have failed previous biologics. Information about the inclusion/exclusion criteria, recruitment processes and baseline characteristics of study populations are thus needed to inform indirect comparisons.

The complex and heterogeneous nature of SpA confounds the identification of a single representative outcome measure [28]. Although composite scores have been developed to assess disease activity in rheumatoid arthritis, the identification of a common composite measure for SpA conditions, including PsA, has proved more challenging due to the involvement of multiple organ systems and the variety of clinical presentations [28]. For axial SpA, including AS, the Ankylosing Spondylitis Disease Activity Score (ASDAS) is increasingly used, while in PsA, the use of different measures, such as the Composite Psoriatic Arthritis Disease Activity Index (CPDAI), the Psoriatic Arthritis Disease Activity Score (PASDAS), Minimal Disease Activity (MDA) and the Disease Activity Index for Psoriatic Arthritis (DAPSA), illustrates that no consensus has yet been reached. As there are limited data available for more recently developed outcomes (e.g. ASDAS), this restricts the utility of this outcome in MAICs. In addition, the heterogeneity of the individual disease manifestations

Table 1 Advantages/disadvantages of NMA and MAIC

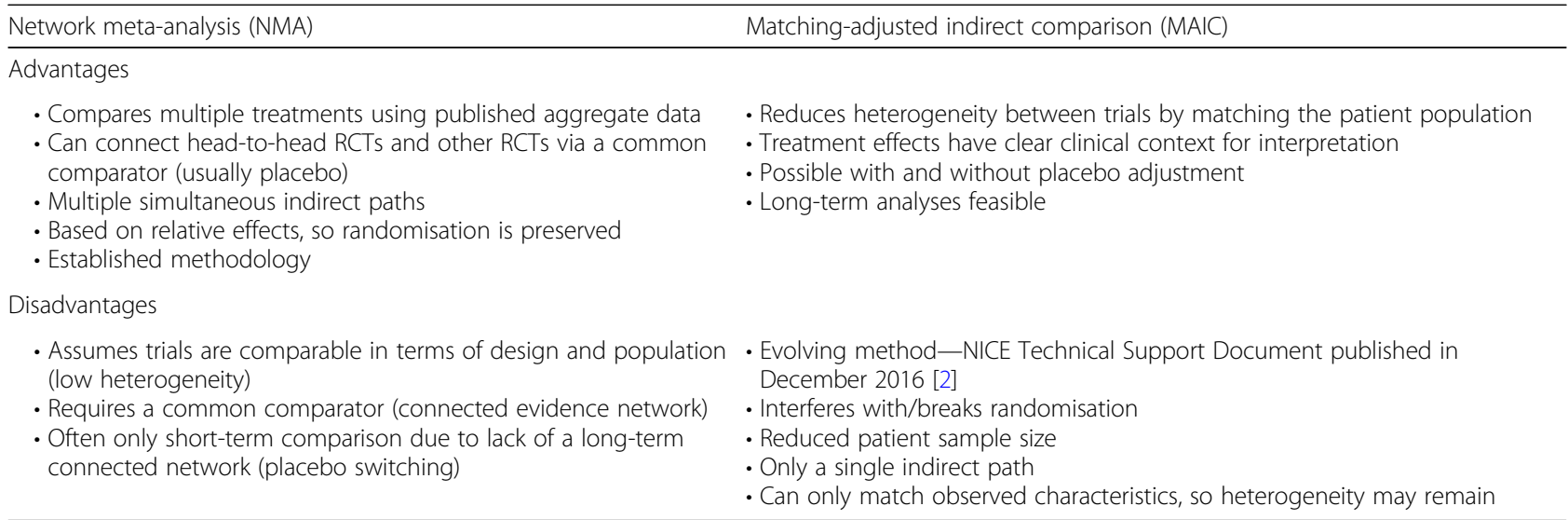


Table 2 Overview of published MAIC in SpA*

\begin{tabular}{|c|c|c|c|c|}
\hline \multirow[t]{2}{*}{ Year } & Patient-level data & Published data & \multirow[t]{2}{*}{ Sponsor } & \multirow[t]{2}{*}{ Type of publication } \\
\hline & Treatment A (trial name; ClinicalTrials.gov identifier) & Treatment B (trial name; ClinicalTrials.gov identifier) & & \\
\hline \multicolumn{5}{|c|}{ Ankylosing spondylitis } \\
\hline 2016 & Secukinumab (MEASURE 2; NCT01649375) & Adalimumab (ATLAS; NCT00195819) & Novartis & Abstract [5] \\
\hline 2016 & Adalimumab (ATLAS; NCT00195819) & $\begin{array}{l}\text { Secukinumab (pooled MEASURE } 1 \\
\text { [NCT01358175], MEASURE } 2 \text { [NCT01649375]) }\end{array}$ & Abbvie & Abstract [6] \\
\hline 2016 & Secukinumab (MEASURE 2; NCT01649375) & Adalimumab (ATLAS; NCT00195819) & Novartis & Abstract [7] \\
\hline 2016 & Secukinumab (MEASURE 1; NCT01358175) & Adalimumab (ATLAS; NCT00195819) & Novartis & Abstract $[8]$ \\
\hline 2016 & $\begin{array}{l}\text { Secukinumab (pooled MEASURE } 1 \text { [NCT01358175], } \\
\text { MEASURE } 2 \text { [NCT01649375]) }\end{array}$ & Adalimumab (ATLAS; NCT00195819) & Novartis & Abstract [9] \\
\hline 2017 & $\begin{array}{l}\text { Secukinumab (pooled FUTURE } 1 \text { [NCT01392326], } \\
\text { FUTURE } 2 \text { [NCT01752634]) }\end{array}$ & Golimumab (GO-RAISE; NCT00265083) & Novartis & Abstract [10] \\
\hline 2017 & $\begin{array}{l}\text { Secukinumab (pooled FUTURE } 1 \text { [NCT01392326], } \\
\text { FUTURE } 2 \text { [NCT01752634]) }\end{array}$ & Golimumab (GO-RAISE; NCT00265083) & Novartis & Abstract [11] \\
\hline $2017^{a}$ & Secukinumab (MEASURE 2; NCT01649375) & Adalimumab (ATLAS; NCT00195819) & Novartis & Abstract [12] \\
\hline \multicolumn{5}{|c|}{ Psoriatic arthritis } \\
\hline 2013 & Adalimumab (ADEPT; NCT00195689) & $\begin{array}{l}\text { Etanercept (Mease et al. 2004), infliximab } \\
\text { (IMPACT 2; NCT00051623) }\end{array}$ & Abbvie & Manuscript [13] \\
\hline 2015 & Adalimumab (ADEPT; NCT00195689) & $\begin{array}{l}\text { Secukinumab (pooled FUTURE } 1 \\
\text { [NCT01392326], FUTURE } 2 \text { [NCT01752634]) }\end{array}$ & Abbvie & Abstract [14] \\
\hline 2016 & Secukinumab (FUTURE 2; NCT01752634) & Adalimumab (ADEPT; NCT00195689) & Novartis & Abstract [15] \\
\hline 2016 & Secukinumab (FUTURE 2; NCT01752634) & Adalimumab (ADEPT; NCT00195689) & Novartis & Abstract [16] \\
\hline 2016 & Secukinumab (FUTURE 2; NCT01752634) & Etanercept (Mease et al. 2004) & Novartis & Abstract [17] \\
\hline 2016 & $\begin{array}{l}\text { Secukinumab (pooled FUTURE } 1 \text { [NCT01392326], } \\
\text { FUTURE } 2 \text { [NCT01752634]) }\end{array}$ & Adalimumab (ADEPT; NCT00195689) & Novartis & Abstract [18] \\
\hline 2016 & Secukinumab (FUTURE 2; NCT01752634) & Infliximab (IMPACT 2; NCT00051623) & Novartis & Abstract [19] \\
\hline $2016^{a}$ & Secukinumab (FUTURE 2; NCT01752634) & Adalimumab (ADEPT; NCT00195689) & Novartis & Abstract [20] \\
\hline 2017 & $\begin{array}{l}\text { Secukinumab (pooled FUTURE } 1 \text { [NCT01392326], } \\
\text { FUTURE } 2 \text { [NCT01752634]) }\end{array}$ & Interferon (IMPACT 2; NCT00051623) & Novartis & Abstract [21] \\
\hline $2017^{\mathrm{a}}$ & Secukinumab (FUTURE 2; NCT01752634) & Infliximab (IMPACT 2; NCT00051623) & Novartis & Abstract [22] \\
\hline $2017^{\mathrm{a}}$ & Secukinumab (FUTURE 2; NCT01752634) & Etanercept (Mease et al. 2004) & Novartis & Abstract [23] \\
\hline $2017^{a}$ & Secukinumab (FUTURE 2; NCT01752634) & Adalimumab (ADEPT; NCT00195689) & Novartis & Abstract [24] \\
\hline 2017 & Adalimumab (ADEPT; NCT00195689) & $\begin{array}{l}\text { Secukinumab (pooled FUTURE } 1 \\
\text { [NCT01392326], FUTURE } 2 \text { [NCT01752634]) }\end{array}$ & Abbvie & Manuscript [25] \\
\hline
\end{tabular}

*Up to December 2017

${ }^{a}$ Cost per responder analysis

included in composite scores may limit which score is compared in MAICs. For example, in ASDAS, C-reactive protein or erythrocyte sedimentation rate values are included, both of which may be affected by biologic disease-modifying antirheumatic drugs (DMARDs); however, neither of these are included in the Bath Ankylosing Spondylitis Disease Activity Index (BASDAI). Since not every patient with axial SpA will show a positive inflammatory finding in their laboratory examination or even fluctuation of these parameters, treatment with biologic DMARDs may affect ASDAS scores more in patients with inflammation than in those without [29]. Thus, certain composite scores may be more difficult to weigh the individual populations based on the heterogeneity of the individual disease manifestations.

Patient-reported outcomes (PROs) are important for consideration in health economic models for SpA owing to the considerable impact of PsA and AS on health-related quality of life. A recent systematic review identified 60 unique PRO measures for SpA, which differed in their degree of correlation with clinical variables [30]. The same study identified a lack of validation of PROs for use across SpA subtypes. For individual SpA subtypes, PROs used include the BASDAI and the Bath Ankylosing Spondylitis Functional Index (BASFI) in AS, while the Psoriatic 
Arthritis Quality of Life (PsAQoL) and Health Assessment Questionnaire Disability Index (HAQ-DI) are used in PsA. Little data is available on the use of these PROs in MAICs. In the two published MAICs in PsA, no statistically significant differences were observed between treatment arms in measurements of HAQ-DI, although differences in efficacy were noted in other more stringent endpoints, such as ACR and PASI response rates [13, 25]. Further research is needed on the effectiveness of comparing treatment effects on PROs using MAICs.

Another key challenge in SpA is the lack of reliable biomarkers of disease activity, structural damage and new bone formation [27]. Proxy outcomes representative of the underlying disease process, discomfort and/or disability are, therefore, frequently used in rheumatology clinical studies (e.g. disease activity outcome measures, such as the American College of Rheumatology (ACR) 20, are used as primary outcomes to discriminate the efficacy of newer drugs from placebo in RCTs, despite the fact that these parameters are not used clinically) $[27,28]$.

\section{Endpoints for MAICs in spondyloarthritis}

Clinically meaningful hard endpoints are needed to demonstrate the additional value (e.g. improved disease status, long-term safety or reduced radiographic progression) of treatments for comparisons on the relative effectiveness to be made. Progression of joint damage is considered irreversible in SpA, and its prevention is an important treatment goal; this outcome can be assessed using imaging and a validated proxy scoring system, such as the modified Stoke Ankylosing Spondylitis Spinal Score (mSASSS) in AS and axial SpA [31], and by various scores of radiographic damage in hands and forefeet (e.g. the Sharp van der Heijde [SHS] method) in PsA [32]. While the mSASSS and the SHS are currently the most used measures of structural damage [33, 34], magnetic resonance imaging (MRI) has been proposed as a potentially more sensitive alternative [35]. Achieving remission, or low disease activity, which is the ultimate goal of SpA treatment [27], is also an example of clinically meaningful hard endpoints for head-to-head studies.

In contrast to the relatively rapid progression reported in rheumatoid arthritis [36], structural changes in axial SpA/AS generally take several years to progress. The shortest follow-up time in AS, based on the reliability and sensitivity to change of the mSASSS, is 2 years [37], while radiographic damage in PsA can be detected within 2 years of disease onset in almost half of patients [38]. The duration required to assess radiographic endpoints is, therefore, an important consideration when conducting comparative studies in SpA.

\section{Considerations for future head-to-head studies}

Sample size estimations take into account the study design (superiority, equivalence, non-inferiority) and the study outcomes. Since more domains (axial and peripheral involvement, arthritis, enthesitis, dactylitis, psoriasis, uveitis, IBD etc.) have to be considered in SpA assessments, the identification of primary and secondary endpoints and sample size estimations are key issues when planning head-to-head studies. Whole-body MRI is a promising new technique for future clinical trials, as it allows assessment of both peripheral and axial joints and entheses [39].

Aside from traditional head-to-head studies, of which there are few published in SpA, a number of other comparative study designs exist, including trials comparing strategies instead of individual drugs and trials with an active control treatment arm. The TIght COntrol of Psoriatic Arthritis (TICOPA) trial-the first and only pragmatic $\mathrm{RCT}$ in PsA-compared intensive management versus standard care in early PsA [40]. The recently published SPIRIT P1 trial in PsA is an example of a placebo- and active-controlled clinical trial that compared two regimens of ixekizumab and an active adalimumab reference arm to treatment with placebo (note: the study was not powered to directly compare adalimumab and ixekizumab) [41].

\section{Conclusions}

Indirect comparisons may be used to infer the relative effectiveness of different treatments in the absence of head-to-head data and can supplement the evidence from traditional sources. MAICs provide an important technique to control for differences in study design and population [13]; however, the greater the imbalance in the study design and/or population characteristics, the lower the actual sample size/precision of the analysis. Allowing academic researchers access to anonymised patient-level data from clinical trials may help improve the quality of MAICs as full data sets from each study could be compared. MAICs, unlike network meta-analyses, are of value for longer-term comparisons beyond the placebo-controlled phase of clinical trials; this is an important consideration for chronic diseases like AS and PsA whose management focuses on long-term treatment goals. Care should be taken when choosing endpoints to compare in longer-term extension arms, as some can be influenced by issues of unblinding and expectation bias owing to the lack of a concurrent placebo arm. Although MAICs have a number of limitations, including the exploratory nature of the analysis, they may be of particular value in generating hypotheses to inform the design of head-to-head studies. Despite these limitations, drug reimbursement agencies, such as the Australian Pharmaceutical Benefits Advisory Committee (PBAC), the UK NICE, the Scottish Medicines Consortium (SMC) and the Canadian Agency for Drug and Technologies in Health (CADTH), are increasingly accepting MAIC as a means of comparative effectiveness [42]. Improvements in the selection of clinical study endpoints and the general reporting of 
clinical trial data in SpA could greatly improve the quality of data to allow more informative indirect comparisons between the myriad of emerging therapies for SpA.

\begin{abstract}
Abbreviations
AS: Ankylosing spondylitis; ASDAS: Ankylosing Spondylitis Disease Activity Score; BASDAl: Bath Ankylosing Spondylitis Disease Activity Index; BASFI: Bath Ankylosing Spondylitis Functional Index; CADTH: Canadian Agency for Drug and Technologies in Health; CPDAl: Composite Psoriatic Arthritis Disease Activity Index; DAPSA: Disease Activity Index for Psoriatic Arthritis; DMARDs: Disease-modifying antirheumatic drugs; HAQ-DI: Health Assessment Questionnaire Disability Index; IBD: Inflammatory bowel disease; MAIC: Matching-adjusted indirect comparison; MDA: Minimal disease activity; MRI: Magnetic resonance imaging; mSASSS: Modified Stoke Ankylosing Spondylitis Spinal Score; NICE: National Institute for Health and Care Excellence; PASDAS: Psoriatic Arthritis Disease Activity Score; PBAC: Pharmaceutical Benefits Advisory Committee; PRO: Patient-reported outcome; PsA: Psoriatic arthritis; PsAQoL: Psoriatic Arthritis Quality of Life; RCT: Randomised controlled trial; SHS: Sharp van der Heijde score; SMC: Scottish Medicines Consortium; SpA: Spondyloarthritis; TICOPA: Tlght COntrol of Psoriatic Arthritis; UK: United Kingdom
\end{abstract}

\section{Acknowledgements}

The authors thank Howard Thom for his input in developing Table 1. The authors also thank Aisling O'Keeffe, PhD and Martin Wallace, PhD for providing medical writing support, which was funded by Novartis in accordance with Good Publication Practice (GPP3) guidelines (http:// www.ismpp.org/gpp3).

\section{Funding}

Not applicable.

\section{Availability of data and materials}

Data sharing is not applicable to this article as no datasets were generated or analysed during the current study.

\section{Authors' contributions}

All co-authors have contributed significantly to this review and approved the final manuscript for submission.

\section{Ethics approval and consent to participate}

Not applicable.

\section{Consent for publication}

Not applicable.

\section{Competing interests}

E. Choy reports non-financial support from Novartis during the preparation of this manuscript and grants and personal fees outside of the submitted work from AbbVie, Allergan, Amgen, AstraZeneca, Biogen, BMS, Boehringer Ingelheim, Celgene, Chugai Pharma, Daiichi Sankyo, Eli Lilly, Ferring Pharmacuetical, GSK, Hospira, ISIS, Jazz Pharmaceuticals, Janssen, Medlmmune, Merrimack Pharmaceutical, MSD, Napp, Novimmune, Novartis, Pfizer, Regeneron, Roche, R-Pharm, Sanofi-Aventis, Synovate, Tonix and UCB. X. Baraliakos reports non-financial support from Novartis during the preparation of this manuscript and grants and personal fees from AbbVie, Merck, Pfizer, UCB, Novartis and Chugai. F. Behrens reports non-financial support from Novartis during the preparation of this manuscript and grants and personal fees from AbbVie, Pfizer, Merck Sharp \& Dohme, UCB, Celgene, Sandoz, Boehringer, Novartis, Chugai and Janssen. S. D'Angelo reports non-financial support from Novartis during the preparation of this manuscript and grants and personal fees from Abbvie, Bristol-Myers Squibb, Celgene, Janssen, Merck Sharp \& Dohme, Novartis, Pfizer and UCB. K. de Vlam reports non-financial support from Novartis during the preparation of this manuscript. B.W. Kirkham reports non-financial support from Novartis during the preparation of this manuscript and, outside the submitted work, grants from AbbVie, grants and personal fees from Novartis, Eli Lilly and Roche, and personal fees from Abbott, BMS, Chugai, MSD, Pfizer and UCB. M. Østergaard reports non-financial support from Novartis, during the preparation of this manuscript, and, outside the submitted work, personal fees from Boehringer Ingelheim, grants and personal fees from Celgene, Merck and Novartis, grants from Centocor and personal fees from Pfizer, Eli-Lilly, Roche, UCB, Abbvie, BMS, Hospira, Orion and Regeneron. G.A. Schett reports non-financial support from Novartis, during the preparation of this manuscript. M. Rissler is an employee of Novartis. K. Chaouche-Teyara is an employee and shareholder of Novartis. C. Perella is an employee and shareholder of Novartis.

\section{Publisher's Note}

Springer Nature remains neutral with regard to jurisdictional claims in published maps and institutional affiliations.

\section{Author details}

${ }^{1}$ CREATE Centre, Division of Infection and Immunity, Cardiff University School of Medicine, Wales, UK. ${ }^{2}$ Rheumazentrum Ruhrgebiet, Ruhr-University Bochum, Herne, Germany. ${ }^{3} \mathrm{CIRI} /$ Rheumatology and Fraunhofer TMP, Goethe-University, Frankfurt, Germany. ${ }^{4}$ Rheumatology Department of Lucania and Rheumatology Institute of Lucania (IRel), San Carlo Hospital of Potenza, Potenza, Italy. ${ }^{5}$ Division of Rheumatology, University Hospitals Leuven, and Skeletal Biology and Engineering Research Center, Department of Development and Regeneration, KU Leuven, Leuven, Belgium. 'Guy's and St Thomas' NHS Foundation Trust, London, UK. ${ }^{7}$ Copenhagen Center for Arthritis Research (COPECARE), Center for Rheumatology and Spine Diseases, Rigshospitalet, Glostrup, and Department of Clinical Medicine, University of Copenhagen, Copenhagen, Denmark. ${ }^{8}$ Friedrich-Alexander University Erlangen-Nurnberg and Universitätsklinikum Erlangen, Erlangen, Germany. ${ }^{9}$ Novartis Pharma AG, Basel, Switzerland.

Received: 25 October 2018 Accepted: 4 January 2019 Published online: 22 January 2019

\section{References}

1. Ishak KJ, Proskorovsky I, Benedict A. Simulation and matching-based approaches for indirect comparison of treatments. Pharmacoeconomics. 2015;33:537-49.

2. World Medical Association I. Declaration of Helsinki. Ethical principles for medical research involving human subjects. J Indian Med Assoc. 2009;107:403-5.

3. Leucht S, Chaimani A, Cipriani AS, Davis JM, Furukawa TA, Salanti G. Network meta-analyses should be the highest level of evidence in treatment guidelines. Eur Arch Psychiatry Clin Neurosci. 2016;266:477-80.

4. Song F, Harvey I, Lilford R. Adjusted indirect comparison may be less biased than direct comparison for evaluating new pharmaceutical interventions. J Clin Epidemiol. 2008:61:455-63.

5. Maksymowych W, Strand V, Baeten D, Nash P, Thom H, Cure S, et al. Secukinumab for the treatment of ankylosing spondylitis: comparative effectiveness results versus adalimumab using a matching-adjusted indirect comparison. Ann Rheum Dis. 2016;75(Suppl2):98.

6. Betts KA, Mittal M, Song J, Skup M, Joshi A. Relative efficacy of adalimumab versus secukinumab in active ankylosing spondylitis: a matching-adjusted indirect comparison. Ann Rheum Dis. 2016;75(Suppl2):98-9.

7. Maksymowych W, Strand V, Baeten D, Nash P, Thom H, Hunger M, et al. Secukinumab for the treatment of ankylosing spondylitis: comparative effectiveness results versus adalimumab using a matching-adjusted indirect comparison. Clin Exp Rheumatol. 2016;34(4):782.

8. Nash P, Baeten D, Strand V, Thom H, Hunger M, Porter B, et al. Secukinumab for ankylosing spondylitis: comparative effectiveness results versus adalimumab using a matching-adjusted indirect comparison. Int J Rheum Dis. 2016;19(Suppl 2):244-5.

9. Maksymowych WP, Strand V, Nash P, Thom H, Karabis A, Gandhi K, et al. Comparative effectiveness of secukinumab and adalimumab in ankylosing spondylitis as assessed by matching-adjusted indirect comparison: an analysis based on all pivotal phase 3 clinical trial data [abstract]. Arthritis Rheumatol. 2016;68(suppl 10).

10. Maksymowych W, Choy E, Yazici Y, Walsh J, Thom H, Kalyvas C, et al. Comparative effectiveness of secukinumab and golimumab in ankylosing spondylitis assessed by matching-adjusted indirect comparison using pivotal phase 3 clinical trial data. Ann Rheum Dis. 2017;76(supplement 2):1301.

11. Maksymowych W, Choy E, Yazici Y, Walsh J, Thom H, Kalyvas C, et al. Comparative effectiveness of secukinumab and golimumab in ankylosing spondylitis: assessed by matching-adjusted indirect comparison using pivotal phase 3 clinical trial data [abstract]. Arthritis Rheumatol. 2017: 69(suppl 10). 
12. Alhammad A, Alalwan A, Alshehri N, Zakaria N, Alkateb L, Zazaa A, et al. Cost per responder analysis comparing secukinumab vs adalimumab for the treatment of ankylosing spondylitis at 52 weeks in Saudi Arabia. Int J Rheum Dis. 2017;20(suppl 1):17-131.

13. Kirson NY, Rao S, Birnbaum HG, Kantor E, Wei RS, Cifaldi M. Matchingadjusted indirect comparison of adalimumab vs etanercept and infliximab for the treatment of psoriatic arthritis. J Med Econ. 2013;16:479-89.

14. Betts KA, Mittal M, Joshi A, Song J, Bao Y. Relative efficacy of adalimumab versus secukinumab in active psoriatic arthritis: a matching-adjusted indirect comparison [abstract]. Arthritis Rheumatol. 2015;67(suppl 10).

15. Nash P, Mclnnes IB, Mease P, Thom H, Cure S, Palaka E, et al. Secukinumab for the treatment of psoriatic arthritis: comparative effectiveness results versus adalimumab up to 48 weeks using a matching-adjusted indirect comparison. Ann Rheum Dis. 2016;75(Suppl2):353-4.

16. Kavanaugh A, McInnes IB, Mease PJ, Hall S, Chinoy H, Kivitz AJ, et al. Efficacy of subcutaneous secukinumab in patients with active psoriatic arthritis stratified by prior tumor necrosis factor inhibitor use: results from the randomized placebo-controlled FUTURE 2 study. J Rheumatol. 2016;43:1713-7.

17. Nash P, Mclnnes IB, Mease P, Thom H, Hunger M, Pricop L, et al. Secukinumab for psoriatic arthritis: comparative effectiveness results versus Etanercept up to 24 weeks using a matching-adjusted indirect comparison. Int J Rheum Dis. 2016;19(Suppl 2):163.

18. Nash P, Mclnnes IB, Mease PJ, Choy EH, Thom H, Kalyvas C, et al. Secukinumab for the treatment of psoriatic arthritis: comparative effectiveness versus adalimumab using a matching-adjusted indirect comparison [abstract]. Arthritis Rheumatol. 2016;68(suppl 10).

19. Strand V, Mease PJ, Mclnnes IB, Nash P, Thom H, Hunger M, et al. Secukinumab for the treatment of psoriatic arthritis: comparative effectiveness versus infliximab using a matching-adjusted indirect comparison [abstract]. Arthritis Rheumatol. 2016;68(suppl 10).

20. Greenberg JD, Nikoglou E, Gunda P, Palmer J, Jugl S. Comparison of secukinumab vs adalimumab in a cost per responder analysis based on a matching-adjusted indirect comparison of efficacy data for the treatment of psoriatic arthritis at 48 weeks from the US perspective [abstract]. Arthritis Rheumatol. 2016;68(suppl 10).

21. Strand V, Mclnnes IB, Mease P, Choy E, Nash P, Thom H, et al. Comparative effectiveness of secukinumab and infliximab in psoriatic arthritis assessed by matching-adjusted indirect comparison using pivotal phase 3 clinical trial data [abstract]. Ann Rheum Dis. 2017;76(supplement 2):957.

22. Alhammad A, Alalwan A, Alshehri N, Zakaria N, Kateb LA, Zazaa A, et al. Cost per responder analysis comparing secukinumab vs infliximab for the treatment of proriatic arthritis at 48 weeks in Saudi Arabia. Int J Rheum Dis. 2017;20(suppl 1)

23. Alhammad A, Alalwan A, Alshehri N, Zakaria N, Kateb LA, Zazaa A, et al. Cost per responder analysis comparing secukinumab vs etanercept for the treatment of psoriatic arthritis at 24 weeks in Saudi Arabia. Int J Rheum Dis. 2017;20(suppl 1):17-131.

24. Alhammad A, Alalwan A, Alshehri N, Zakaria N, Alkateb L, Zazaa A, et al. Cost per responder analysis comparing secukinumab vs adalimumab for the treatment of psoriatic arthritis at 48 weeks in Saudi Arabia. Int J Rheum Dis. 2017;20(suppl 1):17-131

25. Strand V, Betts KA, Mittal M, Song J, Skup M, Joshi A. Comparative effectiveness of adalimumab versus secukinumab for the treatment of psoriatic arthritis: a matching-adjusted indirect comparison. Rheumatol Ther. 2017:4:349-62.

26. Phillippo DM, Ades AE, Dias S, Palmer S, Abrams KR, Welton NJ. National Institute for Health and Care Excellence (NICE) Decision Support Unit (DSU). Technical support document 18: methods for population-adjusted indirect comparisons in submissions to NICE. 2016. Available from: scharr.dept.shef. ac.uk/nicedsu/wp-content/uploads/sites/7/2017/05/Population-adjustmentTSD-FINAL.pdf . Accessed Dec 2017.

27. Paramarta JE, Baeten D. Spondyloarthritis: from unifying concepts to improved treatment. Rheumatology (Oxford). 2014;53:1547-59.

28. Fransen J, van Riel PL. Outcome measures in inflammatory rheumatic diseases. Arthritis Res Ther. 2009;11:244

29. Baraliakos X, Sieper J, Chen S, Pangan AL, Anderson JK. Non-radiographic axial spondyloarthritis patients without initial evidence of inflammation may develop objective inflammation over time. Rheumatology (Oxford). 2017:56:1162-6.

30. Png K, Kwan YH, Leung YY, Phang JK, Lau JQ, Lim KK, et al. Measurement properties of patient reported outcome measures for spondyloarthritis: a systematic review. Semin Arthritis Rheum. 2018:48:274-82.
31. Creemers MC, Franssen MJ, van 't Hof MA, Gribnau FW, van de Putte LB, van Riel PL. Assessment of outcome in ankylosing spondylitis: an extended radiographic scoring system. Ann Rheum Dis. 2005;64:127-9.

32. van der Heijde D. How to read radiographs according to the Sharp/van der Heijde method. J Rheumatol. 2000;27:261-3.

33. Wanders AJ, Landewe RB, Spoorenberg A, Dougados M, van der Linden S, Mielants $\mathrm{H}$, et al. What is the most appropriate radiologic scoring method for ankylosing spondylitis? A comparison of the available methods based on the Outcome Measures in Rheumatology Clinical Trials filter. Arthritis Rheum. 2004;50:2622-32.

34. Tillett W, Jadon D, Shaddick G, Robinson G, Sengupta R, Korendowych E, et al. Feasibility, reliability, and sensitivity to change of four radiographic scoring methods in patients with psoriatic arthritis. Arthritis Care Res (Hoboken). 2014;66:311-7.

35. Glinatsi D, Bird P, Gandjbakhch F, Mease PJ, Boyesen P, Peterfy CG, et al. Validation of the OMERACT Psoriatic Arthritis Magnetic Resonance Imaging Score (PSAMRIS) for the hand and foot in a randomized placebo-controlled trial. J Rheumatol. 2015;42:2473-9.

36. Bruynesteyn K, Landewe R, van der Linden S, van der Heijde D. Radiography as primary outcome in rheumatoid arthritis: acceptable sample sizes for trials with 3 months' follow up. Ann Rheum Dis. 2004;63:1413-8.

37. Spoorenberg A, de Vlam K, van der Linden S, Dougados M, Mielants H, van de Tempel $\mathrm{H}$, et al. Radiological scoring methods in ankylosing spondylitis. Reliability and change over 1 and 2 years. J Rheumatol. 2004;31:125-32.

38. Kane D, Stafford L, Bresnihan B, FitzGerald O. A prospective, clinical and radiological study of early psoriatic arthritis: an early synovitis clinic experience. Rheumatology (Oxford) 2003;42:1460-1468.

39. Ostergaard M, Eshed I, Althoff CE, Poggenborg RP, Diekhoff T, Krabbe S, et al. Whole-body magnetic resonance imaging in inflammatory arthritis: systematic literature review and first steps toward standardization and an OMERACT scoring system. J Rheumatol. 2017;44:1699-705.

40. Coates LC, Moverley AR, McParland L, Brown S, Navarro-Coy N, O'Dwyer U,, et al. Effect of tight control of inflammation in early psoriatic arthritis (TICOPA): a UK multicentre, open-label, randomised controlled trial. Lancet. 2015;386:2489-98.

41. Mease PJ, van der Heijde D, Ritchlin CT, Okada M, Cuchacovich RS, Shuler $\mathrm{CL}$, et al. Ixekizumab, an interleukin-17A specific monoclonal antibody, for the treatment of biologic-naive patients with active psoriatic arthritis: results from the 24-week randomised, double-blind, placebo-controlled and active (adalimumab)-controlled period of the phase III trial SPIRIT-P1. Ann Rheum Dis. 2017:76:79-87

42. Kim H, Gurrin L, Ademi Z, Liew D. Overview of methods for comparing the efficacies of drugs in the absence of head-to-head clinical trial data. Br J Clin Pharmacol. 2014;77:116-21.

\section{Ready to submit your research? Choose BMC and benefit from:}

- fast, convenient online submission

- thorough peer review by experienced researchers in your field

- rapid publication on acceptance

- support for research data, including large and complex data types

- gold Open Access which fosters wider collaboration and increased citations

- maximum visibility for your research: over $100 \mathrm{M}$ website views per year

At BMC, research is always in progress.

Learn more biomedcentral.com/submissions 